\title{
REFLECTION
}

\section{What I Wish My Doctor Really Knew: The Voices of Patients With Obesity}

\author{
Janyce Jobnstone ${ }^{1}$ \\ Cherie Herredsberg ${ }^{2}$ \\ Les Lacy ${ }^{3}$ \\ Peg Bayles ${ }^{4}$ \\ Lynn Dierking \\ Arla Houck \\ Margaret Kilpatrick \\ Luanne Kramer $^{8}$ \\ Karen Mason ${ }^{9}$ \\ Carla Mendez $z^{10}$ \\ Frank Scbrotberger ${ }^{11}$ \\ Christie Befort ${ }^{12}$ \\ 'Grinnell, lowa \\ ${ }^{2}$ Smith Center, Kansas \\ ${ }^{3}$ St. Francis, Kansas \\ ${ }^{4}$ Hastings, Nebraska \\ ${ }^{5}$ Fairview, Kansas \\ ${ }^{6}$ Kearny, Nebraska \\ 7 Junction City, Kansas \\ ${ }^{8}$ Hays, Kansas \\ ${ }^{9}$ Webster City, Iowa \\ ${ }^{10}$ Ellsworth, Kansas \\ ${ }^{11}$ Omaha, Nebraska \\ ${ }^{12}$ University of Kansas Medical Center, \\ Kansas City, Kansas
}

Conflicts of interest: authors report none

\section{CORRESPONDING AUTHOR}

Christie Befort, PhD

Department of Population Health

University of Kansas Medical Center 3901 Rainbow Blvd, Mail Stop 1008

Kansas City, KS 66160

cbefort@kumc.edu

\begin{abstract}
Few health care professionals receive comprehensive training in how to effectively help their patients with obesity. Yet patients are often wanting, needing, and looking for help when they go to the doctor. We, as a group of patients with obesity, share our common experiences and needs when going to the doctor from a place of honesty and hope, with the assumption that clinicians want to know what their patients really think and feel. Our "wish list" for a treatment plan may represent an ideal, but our hope is that our language will speak to clinicians about how they can help their patients manage their obesity.

Ann Fam Med 2020;18:169-171. https://doi.org/10.1370/afm.2494.
\end{abstract}

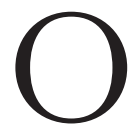
bese-what a cruel word. "O-be-si-ty" — the condition of being grossly fat. A medical diagnosis to describe us. We know it is a medical term, but it can still feel like a cruel word. It's the stigma, the sense that it's a character defect.

We are a group of patients with obesity. Among us are men and women in our early 40s to late 70s, a mix of professionals (including teachers, nurses, dental assistant, farmers, homemakers). But we are individuals with one common denominator: we struggle when it comes to weight management. It has been a lifelong struggle for many of us. Several of us are cancer survivors, and more than a few of us face health complications related to the "condition." We are fighters when it comes to our obesity: we win some battles and lose some battles, but we understand it really is a battle.

We make up a Patient Advisory Board for a primary care randomized trial called RE-POWER (Rural Engagement in Primary Care for Optimizing Weight Reduction). ${ }^{1}$ At one of our meetings, we spent a half day sharing our own experiences and desires in getting help with weight loss from our primary care doctors. We did this in response to a 2017 report that outlined, for the first time, educational competencies for health care professionals in the prevention and treatment of obesity. ${ }^{2}$ The report was the product of a consensus-building process involving representatives from 24 professional organizations including the American Academy of Family Physicians. The competencies highlight the importance of patient interactions, (eg, "use patient-centered communication, discuss obesity in a non-judgmental manner, employ strategies to minimize bias and discrimination"). We noticed, however, that patients themselves were not involved in the process of developing the competencies, and there are varied patient stories that remain hidden. This matches our experience in talking about our weight with our doctors (or our experience in not talking about it) - the discussions are often not as personal, honest, and resourceful as they might be.

If we had to summarize what we want clinicians to know, the most important "competency" if you will, it is this: we want you to know how to look at us, to see each of us as a person. We want you to see us as a person as opposed to an obese person with a certain BMI and a series of condi- 
tions. We know firsthand what it's like for obesity to be treated as an individual failing, a character defect, or a personality flaw. We know all about failure. But we are asking for your help to climb out of the bodies we're in so we can do the things we want to do in order to be ourselves. We need a full-court press from the medical community to help us succeed, and a treatment plan that gets monitored and taken seriously like treatment plans for other conditions.

\section{OUR EXPERIENCE}

Our quest for help, whether we even want to talk about our weight, can begin or end based on our initial experience that either builds or erodes trust. It can be as early as our experience with the front desk staff or how our medical records have been reviewed. We know our weight is recorded and seen at each visit, and we worry that if our obesity is judged as a failing, our records might get a cursory or prejudiced review. We dread feeling judged or like a failure. So, we look for signs that we can trust you and your staff, that you will see us as people, as patients with the same amount of strengths and weaknesses as patients with "normal" BMI.

Because...

I have a doctor's appointment... which I dread. I am thinking, "Will you notice, or say something? Do I want you to? Do you realize I am desperate for help? Do you even really care enough to know me? Are you the right person for this?"

What exactly do I dread when I come to see you? Not making progress with weight loss, feeling like a failure, being judged, being exposed to my own desperation, sharing my personal information with someone I may not trust, wasting my time hoping to get help, thinking it's another day of fighting a battle I often don't believe I can win. If I have lost weight, the appointment will go well, but if I've gained weight, I worry you may be frustrated. At times I lose sleep because I really don't want to come in and get weighed and be told one more time "you need to lose weight." The dread can start days before the visit. I may avoid annual wellness visits for months or years until I've lost a few pounds. Or I may skip a mammogram or other screenings altogether because I don't want to step on the scale. I don't want to see the number, and I don't want anyone to write it down. I see pictures of myself; I already know.

The first thing that happens no matter what my appointment is for (it could be for a mole on my arm) is they take my blood pressure and have me step on the scale. It all starts with the black and white of the number on the scale that day. I can ignore and dance around my weight gain all I want... until I go to the doctor, step on my enemy the scale, and cringe at the number.

I understand my weight affects a myriad of medical conditions. My blood glucose, cholesterol, aching knees, lack of energy, snoring, and depression to name a few. You, as my physician, are brilliant, the top of your class. Years of education, college, medical school, residency-all to tactfully tell me to eat less and exercise. To tell me I am obese. It really is the elephant in the room. I hear you say, "You should drop down to about 2,000 calories, you're clearly eating more than that, and you need to walk a mile a day." And I'm thinking, "That sounds like a great idea. And I don't know how I'm ever going to get it done. I have already tried diet books, expensive meal plans, supplements, and memberships." You tell me to come back in 6 months, and I'm thinking, "what good is that going to do? I'm going to be in the same position if not worse in 6 months." That's when I feel the dread already start for the next visit.

\section{A PLAN}

If I'm diabetic, you've got a plan for me. If I have cancer, you have a plan for me, specialists to see and treatment options. High blood pressure? There are several things we can try. But obesity? I may get a diet sheet and a few pieces of advice. And when I come back in a few months without making any progress and hear the same thing again, I'm thinking, "How can you think the same plan again and again will yield any different results?"

I know you are behind, that you are dealing with patients with cancer and heart disease, rare diseases, and sinus infections. I know you need more than my allotted 15 minutes. But I am here today, and if you don't have time to help me with a plan, who does?

\section{WHAT I NEED MOST}

I need you to not give up on me. Once I had a doctor tell me "every failure means you're going to be more successful next time." I never had a doctor tell me that before. I started losing weight, and sure I failed, but then he picked me up, dusted me off, and said "Well, we know that didn't work, so let's go another route and try something else." That's what I needed to hear.

I don't expect you to have the answer today, but instead of "take this diet sheet I'll see you in 6 months," I need to hear you say "if you're ready, we have a plan for you, we have a nutritionist, and we have a support system that I've heard is helpful." I need you to have a good referral plan, where you would go yourself or send your family. Also have a good behavioral health referral that can help me identify my root cause: anxiety, depression, eating disorders, medical causes. If you address me as a person and ask me if I want to discuss my weight, and I'm not ready, understand you are planting a seed. If you let me know there is help available, I may be ready next time.

I need you to be invested with me for the long haul. I need you to know basic truths about what is effective, but then know how to individualize the diet and exercise guidelines 
based on my medical conditions and root causes. Start with my successes rather than failures. I know failure.

Respect me, inform me, help me. Follow up on my progress, encourage me with realistic goals. Expect me to be accountable and responsible. Even though this is hard, I want it more than you do. More than you can possibly imagine.

We question ourselves: is our desire for a plan realistic, or are we asking for too much? We are reminded about the costs of our disease. Our obesity, at some point, could send any one of us into a major medical event. It may be a heart attack, a stroke, an exacerbation of our diabetes, or a diagnosis of cancer. It may result in an emergency that will take an enormous amount of time, resources, and perhaps our life. We want an effective treatment plan for our obesity and are desperately trying to avoid the emergency department and restore our health.

We are here today, in your clinic, looking for help. Needing results, wanting results. Please see us and help us.
To read or post commentaries in response to this article, see it online at http://www.AnnFamMed.org/content/18/2/169.

Key words: obesity management; competencies; patient voice

Submitted February 28, 2019; submitted, revised, July 29, 2019; accepted August 20, 2019.

Funding support: PCORI OTO-1402-09413.

\section{References}

1. Befort CA, VanWormer JJ, DeSouza C, et al. Protocol for the Rural Engagement in Primary Care for Optimizing Weight Reduction (RE-POWER) Trial: comparing three obesity treatment models in rural primary care. Contemp Clin Trials. 2016;47:304-314.

2. Bradley DW, Dietz WH, the Provider Training and Education Workgroup. Provider competencies for the prevention and management of obesity. https://bipartisanpolicy.org/library/providercompetencies-for-the-prevention-and-management-of-obesity. Published Jun 2017.

\section{Get the Annals of} Family Medicine by E-mail

Editorials I Original Research I Research Briefs I Systematic Reviews I Reflections I Innovations I Departments

\section{Editorial Fellowship: Now accepting applications}

The full text of the journal is available online at hitto:/wwww. annfammed.org and through various gregators, including PubMed Central, EBSCO, and MDConsult. The Annals is indexed in the MEDLINE, Science Citation Index Expanded, Current Contents/Clinical Medicine, EMBASE, and CINHAL databases.

\section{EDITORIALS}

In This Issue: Nothing Simple Kurt C. Stange

\section{The Long Loneliness of Primary Carey} Timothy P. Daaleman

Clinical Prediction Rules: Challenges, Barriers, and Promises Emma Wallace; Michael E. Johansen

\section{ORIGINAL RESEARCH}

Social lsolation and Patient Experience in Older Adults

Takuya Aoki; Yosuke Yamamoto; Tatsuyoshi Ikenoue; Yuka Urushibara-Miyachi; Morito Kise; Yasuki Fujinnuma; Shunichi Fukuhara

Social isolation is associated with a negative patient experience in older primary care patients in Japan. 